\title{
REÚSO DE ÁGUAS RESIDUÁRIAS DA PISCICULTURA E DA SUINOCULTURA NA IRRIGAÇÃO DA CULTURA DA ALFACE ${ }^{1}$
}

\author{
DIRCEU BAUMGARTNER ${ }^{2}$, SILVIO C. SAMPAIO ${ }^{3}$, TATIANA R. DA SILVA ${ }^{4}$, \\ CARLA R. P. A. TEO ${ }^{4}$, MÁRCIO A. VILAS BOAS ${ }^{3}$
}

\begin{abstract}
RESUMO: Este trabalho teve o objetivo de avaliar o desenvolvimento, a produção e a qualidade sanitária da cultura da alface irrigada com águas residuárias originadas da suinocultura e da piscicultura. Os tratamentos avaliados foram: T1 - alface irrigada com água de origem subterrânea e adubação suplementar; T2 - alface irrigada com água residuária de viveiro de peixes alimentados com ração; T3 - alface irrigada com água residuária originária de lagoa de estabilização de dejetos de suínos, e T4 - água de lagoa de cultivo de algas, alimentada com resíduo de biodigestor de dejeto de suíno. Os tratamentos não apresentaram diferenças significativas para altura da alface, diâmetro da cabeça, comprimento da raiz, massa da raiz, massa total da planta, massa fresca e massa seca; os tratamentos T4 e T2 apresentaram os maiores valores para comprimento da maior folha e número de folhas, respectivamente; em geral, as análises foliares e a extração de macro e micronutrientes pela cultura não apresentaram diferenças significativas; ocorreu contaminação de coliformes fecais e totais em todos os tratamentos; não ocorreu contaminação de Escherichia coli em todos os tratamentos; todos os Coeficientes de Uniformidade de Christiansen (CUC) encontrados foram acima de $85 \%$, exceto para o tratamento T3 que foi de $74,05 \%$; ocorreram alterações químicas no solo proporcionais às características das águas utilizadas nos respectivos tratamentos.
\end{abstract}

PALAVRAS-CHAVE: efluente, irrigação, Lactuca sativa L.

\section{REUSE OF WASTEWATER FROM SWINE AND FISH ACTIVITIES IN THE LETTUCE CULTURE}

\begin{abstract}
The objective of this work was to evaluate development, production and sanitary quality of the irrigated lettuce with wastewater from fish and swine activities. The evaluated treatments was: T1 - lettuce irrigated with water from underground origin and supplemental fertilization; T2 - lettuce irrigated with wastewater from fish activities and fish fed with ration; T3 lettuce irrigated with wastewater from swine treated in stabilization lagoon; and T4 - lettuce irrigated with effluent from seaweed lagoon, fed with wastewater from swine activities treated with anaerobic reactor. The treatments did not present significant differences for next culture characteristics: height, diameter head, length root, mass root, total mass plant, green mass and dry mass; the treatments $\mathrm{T} 4$ and $\mathrm{T} 2$ presented the biggest values for length and number leaf, respectively; in general, leaf analyses and extraction of macro and micronutrients by culture did not present significant differences; contamination by fecal coliforms in all treatments occurred; no contamination by Escherichia coli was observed in all treatments; all the Coefficients of Uniformity of Christiansen (CUC) observed were above 85\%, except for treatment T3 where was $74 \%$; chemical alterations in the soil occurred proportional to characteristics of waters used in the treatments.
\end{abstract}

KEYWORDS: effluent, irrigation, Lactuca sativa L.

\footnotetext{
${ }^{1}$ Extraído da dissertação de Mestrado do primeiro autor.

${ }^{2}$ Prof. Assistente, Curso de Engenharia de Pesca, UNIOESTE, Toledo - PR.

${ }^{3}$ Prof. Adjunto, RHESA/CCET, Universidade do Oeste do Paraná, Cascavel - PR, Fone: (0XX45) 3220.3262, ssampaio@unioeste.br; vilasma@unioeste.br

${ }^{4}$ Professor do curso de Nutrição, UNIPAR, Toledo - PR

Recebido pelo Conselho Editorial em: 3-3-2005
}

Aprovado pelo Conselho Editorial em: 4-1-2006 


\section{INTRODUÇÃO}

Atualmente, uma das grandes preocupações refere-se à qualidade das águas superficiais, que vêm sendo utilizadas como suporte para a eliminação dos resíduos produzidos pelo homem. Os problemas de poluição das águas são, em sua maioria, caracterizados pelo crescimento urbano, rural e industrial mal planejado (PORRÉCA, 1998).

BASTOS \& MARA (1992) salientam que a disposição de dejetos no solo vem ganhando espaço, por apresentar pelo menos três vantagens: o tratamento do dejeto, o fornecimento de água e a disponibilidade de nutrientes. Esse mesmo raciocínio aplica-se também às águas residuárias, segundo ALI (1987) e HAMODA \& AL-AWABI (1996), quando afirmam que essas águas podem ser utilizadas na irrigação, principalmente em regiões semi-áridas, desde que se tenha conhecimento específico do seu grau de perigo à saúde e ao ambiente.

A eficiência na produção de diferentes culturas por meio da utilização de águas residuárias é citada por vários autores. ORON et al. (1991b), cultivando algodão, trigo, milho e ervilha, observaram que os sistemas de microirrigação com águas residuárias apresentaram maior rendimento das culturas quando os emissores se encontraram dispostos na superfície do solo, em comparação com a subsuperfície. ORON et al. (1982) verificaram que a irrigação do algodão por gotejamento com águas residuárias possibilitou produtividade de $6.000 \mathrm{~kg} \mathrm{ha}^{-1}$, sem adição de fertilizante químico. VAZQUEZ-MONTIEL et al. (1996) constataram que a cultura do milho, irrigada com águas residuárias, absorveu maior quantidade de nitrogênio na fase de crescimento do que na fase de maturação, acumulando, nessa fase, nitrogênio na forma de nitrato no perfil do solo. MONTE \& SOUSA (1992) observaram que irrigação com águas residuárias de lagoa facultativa aumentou os rendimentos das culturas de milho e de sorgo, além de evitar o uso de quantidades significativas de fertilizantes. OSBURN \& BURKHEAD (1992), em seus estudos com irrigação de pepinos e berinjelas com águas residuárias, concluíram que a água residuária secundária usada não afetou o rendimento das culturas e ocorreu aumento na concentração de nitrogênio e fósforo no solo durante a realização do experimento.

A irrigação com águas residuárias, principalmente em hortaliças, induz uma preocupação latente que é a contaminação por organismos patogênicos. BASTOS \& MARA (1992) concluíram que a qualidade bacteriológica das hortaliças irrigadas com águas residuáriais com qualidade recomendada pela OMS (Organização Mundial de Saúde) não oferece riscos à saúde pública. Os autores observaram, em um sistema de alface irrigada com águas residuárias de lagoa de estabilização, em clima quente e seco, que a interrupção da irrigação garante a descontaminação das plantas e do solo em uma semana. Também no mesmo tipo de clima, COSTA-VARGAS et al. (1991) verificaram que cinco dias após cessada a irrigação com águas residuárias de baixa qualidade, na cultura da alface, ocorreu a descontaminação por Salmonella spp e que os níveis iniciais de coliformes fecais e Escherichia coli foram decrescendo. ORON et al. (1991a) observaram que o gotejamento é o método que apresenta o menor índice de contaminação. Outro ponto importante é que a utilização de águas de rios na irrigação não garante produção isenta de contaminações, como ARAUJO et al. (1999) verificaram em alfaces irrigadas com água de um riacho, índices de coliformes fecais acima de 200 UFC $100 \mathrm{~g}^{-1}$.

Segundo FILGUEIRA (1982), dentre as hortaliças, a alface possui grande importância, pois constitui-se em uma das mais ricas fontes de minerais e de celulose, sendo, contudo, uma cultura que necessita de quantidade de água relativamente grande para que ocorra sua formação (ROWSE, 1974). Irrigação da ordem de $80 \%$ de água disponível no solo apresenta melhor desempenho para o desenvolvimento e produção dessa cultura, segundo DEMATTÊ \& MORETTI FILHO (1981). Nesse sentido, HAMADA (1993) e ALVES (1996) recomendam lâmina média diária próxima de $7,0 \mathrm{~mm} \mathrm{dia}^{-1}$.

Desse modo, o objetivo deste trabalho foi avaliar o desenvolvimento e a contaminação da cultura da alface, as alterações químicas ocorridas no solo e o comportamento do sistema de 
irrigação usado na aplicação de águas residuárias provenientes de atividades de piscicultura e de suinocultura.

\section{MATERIAL E MÉTODOS}

O experimento foi implantado em propriedade rural, localizada no Distrito de São Luís D'Oeste, município de Toledo - PR, cuja localização geográfica é 24\%43'57'S de latitude e 5334'13,1'W de longitude, altitude de $644 \mathrm{~m}$, no período de maio a junho de 2003. O trabalho foi desenvolvido em estufa plástica, abrigando 12 canteiros com dimensões de $1,2 \mathrm{~m}$ x $2 \mathrm{~m}$, sendo 32 mudas de alface por canteiro, da variedade Americana. As plantas foram distribuídas em quatro linhas de oito plantas, com distância de $30 \mathrm{~cm}$ entre as linhas e $25 \mathrm{~cm}$ entre as plantas.

Os tratamentos, baseados em diferentes fontes de água de irrigação, foram: água de poço escavado mais adubação suplementar (T1); efluente de viveiro de cultivo semi-intensivo de Tilápia do Nilo (Oreochromis niloticus), alimentada com ração (T2); efluente de lagoa de estabilização de dejeto suíno, diluído 1:65 (T3), e efluente de lagoa de produção de algas, alimentada com resíduo de biodigestor de dejeto de suíno, diluído 1:5 (T4). As diluições foram realizadas para equilibrar as concentrações de nutrientes existentes das águas utilizadas na irrigação, tomando-se como base o nitrogênio.

O método de irrigação utilizado foi o gotejamento, em virtude de permitir maior controle durante a aplicação das águas utilizadas, evitando o contato direto com a cultura. A irrigação foi feita aplicando-se $7 \mathrm{~mm}$ de efluente por dia, valor esse definido a partir das observações de HAMADA (1993) e principalmente de ALVES (1996), que avaliou a evaporação média e o desenvolvimento da cultura da alface em estufas localizadas em regiões de clima semelhantes ao desta pesquisa. Também foi a lâmina experimental utilizada por LIMA et al. (2005), quando avaliaram os efeitos da água residuária de tratamento de esgotos domésticos na cultura da alface. Destaca-se que o volume de $2.000 \mathrm{~L}$ de água residuária aplicado ao final do ciclo da cultura por tratamento foi bem abaixo dos volumes utilizados por SANDRI et al. (2006) na produção de alface, que aplicaram cerca de $4.800 \mathrm{~L}$ e $20.000 \mathrm{~L}$ de água residuária tratada proveniente de atividades educacionais, nos sistemas de gotejamento e aspersão, respectivamente. Ressalta-se, ainda, que o manejo da irrigação e a quantidade aplicada diária foram idênticos ao trabalho realizado por TAVARES et al. (2005), em que foram aplicados diariamente $50 \mathrm{~L}$ de água residuária por parcela experimental e divididos igualmente nos períodos da manhã e da tarde.

A pressurização do sistema foi feita com bomba centrífuga com potência de $1 / 2 \mathrm{cv}$. Filtros foram usados antes e depois da bomba para prevenir possíveis entupimentos da bomba e da linha gotejadora. Após a bomba, foi instalado um hidrômetro para medir o volume aplicado nas parcelas, e um limitador de pressão que evitou pressões acima de $80 \mathrm{kPa}$. Também foi instalado, após o regulador de pressão, um manômetro para medir as pressões de serviço durante a irrigação. Nas linhas secundárias, foram utilizados canos de $25 \mathrm{~mm}$, e nas linhas gotejadoras, $72 \mathrm{~m}$ de fita gotejadora com vazão de $1,0 \mathrm{~L} \mathrm{~h}^{-1}$.

Seguindo metodologias recomendadas por CLESCERI et al. (1998), determinaram-se características físicas, químicas e microbiológicas referentes às águas de irrigação que constituíram os tratamentos, bem como a estimativa de nutrientes aplicados.

Em cada tratamento, foram determinados os seguintes parâmetros agronômicos: altura da planta, diâmetro da cabeça, comprimento da maior folha, número médio de folhas, comprimento da raiz, massa da raiz, massa total e massa seca. Na obtenção das alturas das plantas, utilizou-se do 
método direto, que consistiu em registrar a distância vertical entre o solo e o ápice da planta, determinada no $9^{\circ} ; 16^{\circ} ; 23^{\circ} ; 30^{\circ}$ e $37^{\circ}$ dias após o transplante. Na determinação do número de folhas, foram contadas folhas com comprimento superior a $1 \mathrm{~cm}$. Após a colheita, as plantas foram pesadas, separando-se a parte vegetativa da raiz, medindo-se as maiores folhas e a raiz de cada planta. Retiraram-se $25 \mathrm{~g}$ de amostras para análise microbiológica, seguindo metodologia de SILVA et al. (2001). O restante do material foi disposto em estufa, a $65{ }^{\circ} \mathrm{C}$, até atingir peso constante, para a realização da análise de matéria seca. Também determinou-se, para cada tratamento, a concentração de macro e micronutrientes na folha, que permitiu estimar a extração de nutrientes do solo realizada pela cultura ao final de seu ciclo, conforme sugerido por SILVA (1999).

Realizou-se avaliação do sistema de irrigação, por meio do Coeficiente de Uniformidade de Christiansen (CUC), com o objetivo de verificar possíveis efeitos dos tratamentos sobre os gotejadores. Também foram realizadas análises químicas de rotina do solo antes e após o experimento, visando a avaliar possíveis alterações frente aos tratamentos. As análises físicas do solo apresentaram constituição de $10,9 \%$ de areia, $59,5 \%$ de silte e $29,6 \%$ de argila.

A partir da coleta dos dados referentes às variáveis avaliadas, foram realizados análises de variância e teste de Tukey, a 5\% de probabilidade.

\section{RESULTADOS E DISCUSSÃO}

De modo geral, comparando a concentração de potássio encontrada em T4 (Tabela 1) com a literatura consultada, percebe-se que essa é superior às concentrações obtidas por MONTE \& SOUSA (1992), OSBURN \& BURKHEAD (1992), HUSSAIN et al. (1996), VAZQUEZMONTIEL et al. (1996) e FONSECA (2001), mas com valores menores que os verificados por HAMODA \& AL-AWABI (1996). Entretanto, as concentrações de potássio nas águas residuárias estavam dentro dos padrões normais para irrigação sugeridos por AYERS \& WESTCOT (1991).

TABELA 1. Análise físico-química e microbiológica das águas utilizadas e totais de nutrientes aplicados nos tratamentos.

\begin{tabular}{|c|c|c|c|c|c|c|c|c|}
\hline \multirow[t]{2}{*}{ Parâmetros } & \multicolumn{4}{|c|}{ Análise Química e Microbiológica } & \multicolumn{4}{|c|}{$\begin{array}{l}\text { Totais de Nutrientes Aplicados } \\
\qquad\left(\mathrm{kg} \mathrm{m}^{-2}\right)\end{array}$} \\
\hline & $\mathrm{T} 1$ & $\mathrm{~T} 2$ & T3 & $\mathrm{T} 4$ & $\mathrm{~T} 1$ & $\mathrm{~T} 2$ & T3 & $\mathrm{T} 4$ \\
\hline $\mathrm{pH}$ & 5,44 & 6,35 & 8,13 & 8,0 & - & - & - & - \\
\hline Sódio $\left(\mathrm{mg} \mathrm{L}^{-1}\right)$ & 6,8 & NR & 170 & 315 & & & & \\
\hline Potássio $\left(\mathrm{mg} \mathrm{L}^{-1}\right)$ & 0,2 & NR & 565 & 450 & 0,07 & - & 193,80 & 154,35 \\
\hline Nitratos $\left(\mathrm{mg} \mathrm{L}^{-1}\right)$ & 1,17 & 0,08 & 0,80 & 0,75 & 0,40 & 0,03 & 0,27 & 0,26 \\
\hline Nitrogênio amoniacal $\left(\mathrm{mg} \mathrm{L}^{-1}\right)$ & 0,61 & 0,50 & NR & NR & - & - & - & - \\
\hline Nitrogênio kjeldahl $\left(\mathrm{mg} \mathrm{L}^{-1}\right)$ & NR & 2,20 & 1.942 & 147,9 & - & 0,76 & 666,11 & 50,73 \\
\hline Fósforo total $\left(\mathrm{mg} \mathrm{L}^{-1}\right)$ & 0,047 & 0,263 & 22,5 & 30,8 & 0,02 & 0,09 & 7,72 & 10,56 \\
\hline $\mathrm{DQO}\left(\mathrm{mg} \mathrm{L}^{-1}\right)$ & NR & 53 & 3.208 & 2.062 & - & - & - & - \\
\hline $\mathrm{DBO}\left(\mathrm{mg} \mathrm{L}^{-1}\right)$ & NR & 8,9 & 987 & 594 & - & - & - & - \\
\hline Coliformes totais (NPM/100 mL) & $>23$ & 1.700 & 50.000 & 90.000 & - & - & - & - \\
\hline Coliformes fecais (NPM/100 mL) & $<1,1$ & 500 & 50.000 & 50.000 & - & - & - & - \\
\hline
\end{tabular}

NR - Análise não-realizada.

Embora as diluições feitas em T3 e T4 tenham sido para equilibrar as quantidades de nitrogênio aplicadas, e sendo esse um elemento necessário ao desenvolvimento da cultura, T4 apresentou maior concentração de nitrogênio total em sua composição. 
As concentrações da maioria dos nutrientes dos tratamentos T3 e T4 foram superiores às obtidas por ALI (1987), MONTE \& SOUSA (1992), OSBURN \& BURKHEAD (1992), VAZQUEZ-MONTIEL et al. (1996) e FONSECA (2001), que aplicaram água residuária doméstica na forma de irrigação.

O tratamento T4 superou os valores encontrados por JUCHEN (2000), que aplicou águas residuárias de laticínio e de frigorífico para irrigação de alface, o que não aconteceu com T3, cujos valores foram inferiores aos do autor mencionado. A concentração do nitrogênio do tratamento T2, mesmo sem ocorrer diluição, foi menor do que as obtidas pelos autores acima citados.

Segundo SPERLING (1996), o nitrogênio na forma de nitrato pode ser associado a doenças, e o seu excesso de aplicação também acarreta contaminação do ambiente. As concentrações de nitrato verificadas nas águas residuárias foram todas inferiores àquelas utilizadas por ALI (1987), MONTE \& SOUSA (1992), OSBURN \& BURKHEAD (1992), HUSSAIN et al. (1996), HAMODA \& AL-AWABI (1996) e VAZQUEZ-MONTIEL et al. (1996), que obtiveram bons resultados aplicando águas residuárias de esgoto doméstico para irrigação de diversas culturas. Segundo AYERS \& WESTCOT (1991) e SPERLING (1996), esse índice de nitrato menor que $10 \mathrm{mg} \mathrm{L}^{-1}$ (como verificado neste estudo) não apresenta restrições ao uso como fonte de água para irrigação.

As concentrações de fósforo verificadas nos tratamentos T2, T3 e T4, como demonstra a Tabela 1, foram inferiores às obtidas por ALI (1987), MONTE \& SOUSA (1992), OSBURN \& BURKHEAD (1992), HAMODA \& AL-AWABI (1996), VAZQUEZ-MONTIEL et al. (1996), JUCHEN (2000) e FONSECA (2001), em respectivas águas residuárias avaliadas e citadas anteriormente. Os valores encontrados nas águas residuárias foram superiores aos estabelecidos pela resolução do CONAMA no 20, de 18-6-86. Segundo SPERLING (1996), o fósforo não apresenta problemas de ordem sanitária, mas pode causar excessivo crescimento de algas e possível entupimento do sistema, sendo necessária a utilização de filtros de tela e discos para a redução desse problema.

A demanda química de oxigênio (DQO) verificada nos tratamentos T2, T3 e T4 foi inferior às obtidas por MONTE \& SOUSA (1992), HAMODA \& AL-AWABI (1996) e JUCHEN (2000), mas superior às encontradas por OSBURN \& BURKHEAD (1992), que obtiveram valores inferiores ao obtido no tratamento T2. Os valores da demanda bioquímica de oxigênio (DBO) nos tratamentos foram inferiores aos detectáveis pelos equipamentos utilizados.

Os resultados das análises de coliformes totais e fecais (Tabela 1) mostram que T2, T3 e T4 possuem maior contagem de coliformes que as águas residuárias utilizadas por JUCHEN (2000), mas não ultrapassaram os valores estabelecidos pela resolução do CONAMA nº 20, de 18-6-86 (SPERLING, 1996), com exceção do tratamento T4, que apresentou maior contagem de coliformes fecais que o estabelecido. Nota-se, também, que as águas residuárias utilizadas no experimento (T2, T3 e T4) apresentaram menor contagem de coliformes que a água residuária utilizada por COSTA-VARGAS et al. (1991), os quais afirmam que, após o período de aplicação e cessada a irrigação por cinco dias antes da colheita, a cultura da alface estaria isenta de contaminação, possibilitando o seu consumo.

As análises de variância e o teste de Tukey, referentes à altura da alface (Tabela 2), mostraram que não houve diferença significativa entre os tratamentos, em relação à altura da planta, durante o período de desenvolvimento da cultura.

A partir dos resultados obtidos, pode-se afirmar que a aplicação de águas residuárias diluídas não prejudicou o crescimento da cultura da alface americana, corroborando os resultados obtidos por RICCI (1993), que não encontrou diferença no crescimento da alface, comparando a adubação convencional e orgânica com vermicompostagem de resíduos agroindustriais. Resultados semelhantes foram obtidos por KALIL (1992) e JUCHEN (2000), que não encontraram diferenças significativas nas alturas da alface irrigada com água residuária e potável. 
TABELA 2. Altura média $(\mathrm{cm})$ da alface americana durante o período de desenvolvimento.

\begin{tabular}{cccccc}
\hline Tratamento & $9^{-0}$ Dia & $16^{-}$Dia & $23^{-}$Dia & $30^{-0}$ Dia & $37^{0}$ Dia \\
\hline T1 & $12,4 \mathrm{a}$ & $13,9 \mathrm{a}$ & $16,1 \mathrm{a}$ & $20,1 \mathrm{a}$ & $23,2 \mathrm{a}$ \\
T2 & $12,5 \mathrm{a}$ & $14,5 \mathrm{a}$ & $16,3 \mathrm{a}$ & $19,9 \mathrm{a}$ & $22,8 \mathrm{a}$ \\
T3 & $12,2 \mathrm{a}$ & $13,9 \mathrm{a}$ & $15,0 \mathrm{a}$ & $19,9 \mathrm{a}$ & $22,9 \mathrm{a}$ \\
T4 & $12,1 \mathrm{a}$ & $13,5 \mathrm{a}$ & $14,8 \mathrm{a}$ & $20,2 \mathrm{a}$ & $23,6 \mathrm{a}$ \\
\hline
\end{tabular}

Médias que apresentam letras iguais, não diferem entre si pelo teste Tukey, a 5\% de probabilidade, na mesma linha.

$\mathrm{Na}$ Tabela 3, percebe-se que não houve diferença significativa entre os tratamentos para diâmetro da cabeça e comprimento da raiz. Os resultados são semelhantes aos obtidos por JUCHEN (2000), que verificou que o diâmetro da cabeça da alface e o número de folhas não variaram significativamente, quando essa planta foi cultivada com águas residuárias de laticínio e de frigorífico.

TABELA 3. Dimensões da alface americana após o período de desenvolvimento.

\begin{tabular}{ccccc}
\hline Tratamento & $\begin{array}{c}\text { Diâmetro da } \\
\text { Cabeça }(\mathrm{cm})\end{array}$ & $\begin{array}{c}\text { Comprimento da } \\
\text { Maior Folha }(\mathrm{cm})\end{array}$ & $\begin{array}{c}\text { Número Médio } \\
\text { de Folhas }\end{array}$ & $\begin{array}{c}\text { Comprimento da Raiz } \\
(\mathrm{cm})\end{array}$ \\
\hline T1 & $38,7 \mathrm{a}$ & $31,0 \mathrm{c}$ & $19,0 \mathrm{ab}$ & $13,5 \mathrm{a}$ \\
T2 & $37,5 \mathrm{a}$ & $32,7 \mathrm{ab}$ & $21,6 \mathrm{a}$ & $12,4 \mathrm{a}$ \\
T3 & $35,9 \mathrm{a}$ & $32,4 \mathrm{~b}$ & $19,4 \mathrm{ab}$ & $12,6 \mathrm{a}$ \\
T4 & $37,3 \mathrm{a}$ & $33,5 \mathrm{a}$ & $18,7 \mathrm{~b}$ & $13,0 \mathrm{a}$ \\
\hline
\end{tabular}

Médias que apresentam letras iguais na mesma coluna, não diferem entre si, pelo teste Tukey, a 5\% de probabilidade.

Por outro lado, por meio dos dados da Tabela 3, verificou-se diferença significativa entre as médias de número de folhas e o comprimento da maior folha. Nota-se que o tratamento T2 obteve o maior número de folhas, diferindo de T4. Os tratamentos T1, T2 e T3 não apresentaram diferença significativa entre si, até mesmo o T4 pode ser considerado semelhante aos demais com nível de $5 \%$ de probabilidade. Apesar de o tratamento T4 ter apresentado menor número de folhas, mas estatisticamente igual ao $\mathrm{T} 1$ e ao $\mathrm{T} 3$, esse, ao final do experimento, apresentou produção semelhante aos outros tratamentos, em virtude do maior comprimento das folhas. Tal fato, possivelmente, tenha ocorrido devido à maior concentração de potássio em suas águas residuárias, o que pode ter causado deficiência induzida de magnésio, prejudicando principalmente as folhas mais velhas (FERREIRA, 1993), sendo os nutrientes aproveitados por outras folhas, aumentando suas dimensões.

Pode-se afirmar, considerando o nível de probabilidade de 5\%, que os resultados obtidos para o número de folhas são semelhantes aos resultados de JUCHEN (2000), em que o autor não obteve diferença no número de folhas da alface, submetida à irrigação com águas residuárias. Também são semelhantes aos resultados de ALVES (1996) e GOMES (1998), que aplicaram diferentes doses de nitrogênio e uréia, respectivamente.

Observando-se a análise de variância e o teste de Tukey (Tabela 4), nota-se que não houve diferença significativa entre as médias das massas das raízes, da massa total, da massa seca e da massa fresca. Observa-se que a aplicação de águas residuárias em substituição à adubação convencional não produziu efeitos diferenciados entre os tratamentos. Essa observação não coincide com o trabalho desenvolvido por JUCHEN (2000), que, aplicando diversos tipos de águas residuárias com mesmas concentrações de nitrogênio, encontrou diferenças nas massas frescas da alface, com superioridade para os tratamentos com águas residuárias de frigorífico. Por outro lado, concordam com os resultados observados por HUSSAIN et al. (1996), cultivando trigo irrigado com águas residuárias, em que não obtiveram diferença nas biomassas, comparado com a adubação convencional. ALVES (1996), fertirrigando alface com adubação nitrogenada, obteve maiores pesos de massa fresca, comparados à adubação convencional. 
TABELA 4. Massas de raiz, total da planta, fresca e seca (g) da alface americana, após o período de desenvolvimento.

\begin{tabular}{ccccc}
\hline Tratamento & Massa da Raiz & Massa Total & Massa Fresca & Massa Seca \\
\hline T1 & $11,4 \mathrm{a}$ & $427,0 \mathrm{a}$ & $415,6 \mathrm{a}$ & $121,4 \mathrm{a}$ \\
T2 & $10,5 \mathrm{a}$ & $417,9 \mathrm{a}$ & $407,3 \mathrm{a}$ & $121,5 \mathrm{a}$ \\
T3 & $10,5 \mathrm{a}$ & $389,6 \mathrm{a}$ & $379,1 \mathrm{a}$ & $100,4 \mathrm{a}$ \\
T4 & $11,1 \mathrm{a}$ & $421,9 \mathrm{a}$ & $410,8 \mathrm{a}$ & $113,0 \mathrm{a}$ \\
\hline
\end{tabular}

Médias que apresentam letras iguais na mesma coluna, não diferem entre si, pelo teste Tukey, a 5\% de probabilidade.

Os valores referentes à massa seca (Tabela 4) são menores que os obtidos por JUCHEN (2000), que aplicou águas residuárias de laticínio, com mesma carga de nitrogênio que as outras fontes de fertirrigação utilizadas. Isso possivelmente ocorreu pelo efeito de outros nutrientes existentes nas águas residuárias, não avaliados pelo autor.

OSBURN \& BURKHEAD (1992), aplicando águas residuárias de esgoto urbano na produção de hortaliças, não encontraram diferença significativa nas dimensões da plantas. Mas os autores salientam que outros trabalhos mostraram influência de águas residuárias secundárias de esgoto urbano na produção de alface, de cebola, de couve-flor e de brócolis.

TAVARES et al. (2005), avaliando os efeitos da água residuária de esgotos domésticos tratada por lagoas de estabilização e da adubação orgânica na produção de alface, observaram que a interação entre ambos os fatores não foi significativa. Também não houve diferenças significativas na altura de planta, diâmetro da cabeça, número de folhas, peso das folhas, peso da raiz, peso total e diâmetro da raiz devido ao fator água residuária. Porém, o fator adubação orgânica apresentou efeito significativo em todos esses parâmetros agronômicos avaliados.

As concentrações de macro e micronutrientes determinadas na folha da cultura para todos tratamentos encontram-se nas Tabelas 5 e 6, respectivamente. Nota-se que não houve diferença significativa nas concentrações médias de nitrogênio, fósforo, potássio, cálcio, magnésio, cobre, zinco, ferro e boro, na parte aérea da alface, submetida à irrigação com águas residuárias, demonstrando novamente indicativo de que a aplicação de águas residuárias não interfere na absorção de alguns nutrientes.

Os resultados encontrados confirmam os obtidos por DANTAS (1997), cultivando alface dentro e fora de casa de vegetação, em que não foram observadas grandes diferenças nas concentrações de nutrientes da alface. RICCI (1993) também não obteve diferença na concentração de nutrientes na parte aérea da planta, comparando a aplicação de adubação orgânica e convencional.

TABELA 5. Concentrações $\left(\mathrm{g} \mathrm{kg}^{-1}\right)$ de macronutrientes.

\begin{tabular}{ccccrc}
\hline Tratamento & $\mathrm{N}$ & $\mathrm{P}$ & $\mathrm{K}$ & $\mathrm{Ca}$ & $\mathrm{Mg}$ \\
\hline T1 & $41,42 \mathrm{a}$ & $6,81 \mathrm{a}$ & $86,50 \mathrm{a}$ & $10,80 \mathrm{a}$ & $2,89 \mathrm{a}$ \\
T2 & $40,83 \mathrm{a}$ & $5,67 \mathrm{a}$ & $86,17 \mathrm{a}$ & $9,97 \mathrm{a}$ & $3,08 \mathrm{a}$ \\
T3 & $39,67 \mathrm{a}$ & $5,29 \mathrm{a}$ & $85,92 \mathrm{a}$ & $10,05 \mathrm{a}$ & $2,77 \mathrm{a}$ \\
T4 & $42,00 \mathrm{a}$ & $5,10 \mathrm{a}$ & $84,33 \mathrm{a}$ & $11,07 \mathrm{a}$ & $3,84 \mathrm{a}$ \\
\hline
\end{tabular}

Médias que apresentam letras iguais na mesma coluna, não diferem entre si, pelo teste Tukey, a 5\% de probabilidade.

TABELA 6. Concentrações $\left(\mathrm{mg} \mathrm{kg}^{-1}\right)$ de micronutrientes na folha.

\begin{tabular}{ccccrr}
\hline Tratamento & $\mathrm{Cu}$ & $\mathrm{Zn}$ & $\mathrm{Mn}$ & \multicolumn{1}{c}{$\mathrm{Fe}$} & \multicolumn{1}{c}{$\mathrm{B}$} \\
\hline T1 & $26,67 \mathrm{a}$ & $47,00 \mathrm{a}$ & $76,17 \mathrm{~b}$ & $7,87 \mathrm{a}$ & $58,48 \mathrm{a}$ \\
T2 & $25,33 \mathrm{a}$ & $45,50 \mathrm{a}$ & $142,67 \mathrm{a}$ & $11,10 \mathrm{a}$ & $75,27 \mathrm{a}$ \\
T3 & $28,33 \mathrm{a}$ & $41,17 \mathrm{a}$ & $124,50 \mathrm{ab}$ & $13,27 \mathrm{a}$ & $100,75 \mathrm{a}$ \\
T4 & $34,33 \mathrm{a}$ & $47,83 \mathrm{a}$ & $72,23 \mathrm{~b}$ & $13,84 \mathrm{a}$ & $75,47 \mathrm{a}$ \\
\hline
\end{tabular}

Médias que apresentam letras iguais na mesma coluna, não diferem entre si, pelo teste Tukey, a 5\% de probabilidade. 
As concentrações de nitrogênio nas alfaces coletadas dos tratamentos possuem valores dentro da faixa de teores adequados para a cultura (30 a $50 \mathrm{~g} \mathrm{~kg}^{-1}$ de massa seca, sugerido por BOARETO et al., 1999). O mesmo ocorreu com as concentrações do fósforo (4 a $\left.7 \mathrm{~g} \mathrm{~kg}^{-1}\right)$, cálcio (15 a $25 \mathrm{~g} \mathrm{~kg}^{-1}$ ), manganês (30 a $150 \mathrm{mg} \mathrm{kg}^{-1}$ ) e do zinco (30 a $100 \mathrm{mg} \mathrm{kg}$ ). Entretanto, as concentrações de potássio e de cobre apresentaram valores acima da faixa adequada para a cultura (50 a $80 \mathrm{~g}$ de $\mathrm{K} \mathrm{kg}^{-1}$ de massa seca e 7 a $20 \mathrm{mg} \mathrm{de} \mathrm{Cu} \mathrm{kg}^{-1}$ de matéria seca, BOARETO et al., 1999). O boro também apresentou valores superiores aos da faixa sugerida por BOARETO et al. (1999) (30 a 60 mg de B kg-1 de massa seca), com exceção do tratamento T1 (58,48 $\left.\mathrm{mg} \mathrm{kg}^{-1}\right)$.

A partir dos resultados das análises de tecido vegetal, é possível notar que o ferro e o magnésio estiveram presentes na composição da alface em menores concentrações que as consideradas adequadas para a cultura (50 a $150 \mathrm{mg}$ de Fe kg${ }^{-1}$ de massa seca e 4 a 6 g de $\mathrm{Mg} \mathrm{kg}^{-1}$ de massa seca, BOARETO et al., 1999).

Observa-se, pelas Tabelas 7 e 8 , que não houve diferença significativa nas médias das extrações dos elementos do solo pela parte aérea da cultura da alface americana, quando aplicados os tratamentos. A partir desses resultados, é possível confirmar as citações de MONTE \& SOUSA (1992), OSBURN \& BURKHEAD (1992), HUSSAIN et al. (1996), VAZQUEZ-MONTIEL et al. (1996), JUCHEN (2000) e FONSECA (2001) de que, após pré-tratamento ou diluição, as águas residuárias oferecem quantidade de nutrientes suficiente para o desenvolvimento de culturas. ALI (1987) acrescenta ainda que os níveis de tratamento ou de diluição deveriam ser determinados regionalmente e não como são propostos mundialmente.

Autores como SOUSA (2000), mesmo fertirrigando alface com diferentes doses de potássio, não observaram diferença na absorção e acúmulo de nutrientes na parte aérea da planta, como também SANDRI et al. (2006), quando avaliaram os teores de nutrientes na alface irrigada com água residuária de atividades educacionais.

TABELA 7. Extração (g) de macronutrientes pela cultura.

\begin{tabular}{cccrcc}
\hline Tratamento & $\mathrm{N}$ & $\mathrm{P}$ & $\mathrm{K}$ & $\mathrm{Ca}$ & $\mathrm{Mg}$ \\
\hline T1 & $5,02 \mathrm{a}$ & $0,82 \mathrm{a}$ & $10,49 \mathrm{a}$ & $1,32 \mathrm{a}$ & $0,36 \mathrm{a}$ \\
$\mathrm{T} 2$ & $4,98 \mathrm{a}$ & $0,70 \mathrm{a}$ & $10,49 \mathrm{a}$ & $1,29 \mathrm{a}$ & $0,38 \mathrm{a}$ \\
T3 & $3,91 \mathrm{a}$ & $0,53 \mathrm{a}$ & $8,59 \mathrm{a}$ & $0,97 \mathrm{a}$ & $0,27 \mathrm{a}$ \\
T4 & $4,74 \mathrm{a}$ & $0,57 \mathrm{a}$ & $9,51 \mathrm{a}$ & $1,25 \mathrm{a}$ & $0,43 \mathrm{a}$ \\
\hline
\end{tabular}

Médias que apresentam letras iguais na mesma coluna, não diferem entre si, pelo teste Tukey, a 5\% de probabilidade.

TABELA 8. Extração (mg) de micronutrientes pela cultura.

\begin{tabular}{ccrrrr}
\hline Tratamento & $\mathrm{Cu}$ & $\mathrm{Zn}$ & $\mathrm{Mn}$ & $\mathrm{Fe}$ & \multicolumn{1}{c}{$\mathrm{B}$} \\
\hline $\mathrm{T} 1$ & $3,29 \mathrm{a}$ & $5,83 \mathrm{a}$ & $9,639 \mathrm{a}$ & $0,95 \mathrm{a}$ & $7,04 \mathrm{a}$ \\
$\mathrm{T} 2$ & $3,09 \mathrm{a}$ & $5,63 \mathrm{a}$ & $17,334 \mathrm{a}$ & $1,32 \mathrm{a}$ & $9,10 \mathrm{a}$ \\
$\mathrm{T} 3$ & $2,91 \mathrm{a}$ & $4,08 \mathrm{a}$ & $12,317 \mathrm{a}$ & $1,27 \mathrm{a}$ & $10,25 \mathrm{a}$ \\
T4 & $3,88 \mathrm{a}$ & $5,38 \mathrm{a}$ & $8,147 \mathrm{a}$ & $1,57 \mathrm{a}$ & $8,54 \mathrm{a}$ \\
\hline
\end{tabular}

Médias que apresentam letras iguais na mesma coluna, não diferem entre si, pelo teste Tukey, a 5\% de probabilidade.

Os resultados referentes às análises microbiológicas das folhas são apresentados na Tabela 9. Avaliando-se os níveis de coliformes fecais e totais encontrados, percebe-se que, provavelmente, ao final do ciclo da cultura, deveria ter sido respeitado o período de desinfecção das alfaces, como o recomendado por COSTA-VARGAS et al. (1991). O número de coliformes totais encontrados foi relativamente alto; isso se deveu, possivelmente, por esse grupo existir em abundância no ambiente e não devido à influência dos tratamentos aplicados, como sugere COSTA-VARGAS et al. (1991). Os valores indicadores de contaminação encontrados no experimento foram inferiores aos valores encontrados por COSTA-VARGAS et al. (1991), BASTOS \& MARA (1992) e MONTE \& SOUSA (1992), em seus experimentos. 
Percebe-se, na Tabela 9, que o tratamento com maior incidência de coliformes fecais foi o $\mathrm{T} 3$, em que todas as réplicas apresentaram valores superiores a $2.400 \mathrm{NMP} \mathrm{g}^{-1}$. O tratamento T4 também apresentou índices semelhantes, e a maioria de suas réplicas apresentou valores superiores a $2.400 \mathrm{NMP} \mathrm{g}^{-1}$, demonstrando que, mesmo as águas residuárias não entrando em contato com a parte vegetativa, a contaminação pode ser considerável. O tratamento T2 apresentou menor contaminação que os tratamentos T3 e T4. O tratamento T1 foi o que apresentou menor índice de contaminação, com valores de $28 \mathrm{NMP} \mathrm{g}^{-1}$, para coliformes fecais.

$\mathrm{Na}$ análise microbiológica da alface, percebe-se que não houve contaminação por Escherichia coli em nenhum dos tratamentos.

TABELA 9. Análises microbiológicas da cultura.

\begin{tabular}{cccc}
\hline Tratamento & $\begin{array}{r}\text { Coliformes Totais } \\
\left(\text { NMP g }^{-1}\right)\end{array}$ & $\begin{array}{c}\text { Coliformes Fecais } \\
\left(\text { NMP g }^{-1}\right)\end{array}$ & $\begin{array}{r}\text { Escherichia coli } \\
\left(\text { NMP g }^{-1}\right)\end{array}$ \\
\hline T1 & $\geq 2.400$ & $\geq 28$ & 0 \\
T1 & $\geq 2.400$ & $\geq 28$ & 0 \\
T1 & $\geq 2.400$ & $\geq 28$ & 0 \\
T2 & $\geq 2.400$ & $\geq 20$ & 0 \\
T2 & $\geq 2.400$ & $\geq 64$ & 0 \\
T2 & $\geq 2.400$ & $\geq 2.400$ & 0 \\
T3 & $\geq 2.400$ & $\geq 2.400$ & 0 \\
T3 & $\geq 2.400$ & $\geq 2.400$ & 0 \\
T3 & $\geq 2.400$ & $\geq 2.400$ & 0 \\
T4 & $\geq 2.400$ & $\geq 75$ & 0 \\
T4 & $\geq 2.400$ & $\geq 2.400$ & 0 \\
T4 & $\geq 2.400$ & & 0 \\
\hline
\end{tabular}

No geral, os dados observados para coliformes fecais (Tabela 9) são menores que aqueles encontrados por LIMA et al. (2005), quando trabalharam com esgoto urbano tratado com caixa de areia, tanque de equalização e decantação (Tratamento Primário) e, com UASB e lagoas de polimento (tratamento secundário). Os valores respectivos foram de 7,34 10 5 e 1,16 $10^{6} \mathrm{NMP}$ $(100 \mathrm{~g})^{-1}$ para coliformes; e de 3,60 102 e 9,36 10 $\mathrm{NMP}(100 \mathrm{~g})^{-1}$ para Escherichia coli.

Pela Tabela 10, verifica-se que os tratamentos T1, T2 e T4 propiciaram valores de coeficientes de uniformidade superiores ao limite de $85 \%$ recomendado pela FAO (SOUSA, 2000). Esses valores aproximam-se daqueles observados por ALVES (1996), por GOMES (1998), por SOUSA (2000) e por JUCHEN (2000). A diferença entre os CUCs do tratamento T2 pode ser decorrente da sedimentação do material em suspensão na lagoa de piscicultura, e a do T3 devido, provavelmente, ao alto teor de carga orgânica contida na água desse tratamento, como verificado na Tabela 1.

TABELA 10. Coeficientes de Uniformidade de Christiansen (CUC) para os respectivos tratamentos.

\begin{tabular}{cc}
\hline Tratamento & CUC (\%) \\
\hline T1 & 89,66 \\
T2 & 91,76 \\
T3 & 74,05 \\
T4 & 85,47 \\
\hline
\end{tabular}

Os resultados das análises químicas do solo, antes e após o experimento, podem ser observados na Tabela 11. Verifica-se que houve aumento em praticamente todos os macronutrientes existentes no solo, quando submetidos aos tratamentos. O tratamento que 
apresentou menor acréscimo de nutrientes no solo foi o T2, devido à menor concentração desses nutrientes, comparado aos demais (Tabela 1).

TABELA 11. Alterações químicas do solo frente aos tratamentos.

\begin{tabular}{cccccccccc}
\hline \multirow{2}{*}{ Tratamentos } & $\begin{array}{c}\mathrm{P} \\
\mathrm{mg} \mathrm{dm}\end{array}$ & $\begin{array}{c}\mathrm{MO} \\
\mathrm{g} \mathrm{dm}^{-3}\end{array}$ & $\mathrm{pH}$ & $\mathrm{H}+\mathrm{Al}$ & $\mathrm{Al}$ & $\mathrm{K}$ & $\mathrm{Ca}$ & $\mathrm{Mg}$ & $\mathrm{V}$ \\
\cline { 6 - 8 } & & \multicolumn{5}{c}{$\mathrm{cmol} \mathrm{dm}^{-3}$} \\
Antes & 22,30 & 25,46 & 5,30 & 5,76 & 0,00 & 0,12 & 7,96 & 3,06 & 65,92 \\
\hline T1 & 38,47 & 41,55 & 5,22 & 4,61 & 0,00 & 1,78 & 7,86 & 2,63 & 72,69 \\
T2 & 23,79 & 36,19 & 5,17 & 4,61 & 0,00 & 1,60 & 7,21 & 2,63 & 71,28 \\
T3 & 33,67 & 37,53 & 5,20 & 3,97 & 0,00 & 1,40 & 8,08 & 2,06 & 74,40 \\
T4 & 48,69 & 42,89 & 5,46 & 3,97 & 0,00 & 0,94 & 7,24 & 2,47 & 72,85 \\
\hline
\end{tabular}

\section{CONCLUSÕES}

Os tratamentos constituídos pelas irrigações com água de poço escavado mais adubação suplementar (T1), efluente de um viveiro de cultivo semi-intensivo de Tilápia do Nilo (Oreochromis niloticus), alimentada com ração (T2), efluente de uma lagoa de estabilização de dejeto suíno, diluído 1:65 (T3) e efluente de uma lagoa de produção de algas, alimentada com resíduo de um biodigestor de dejeto suíno, diluído 1:5 (T4), não apresentaram diferenças significativas nas variáveis altura da alface, diâmetro da cabeça, comprimento da raiz, massa da raiz, massa total da planta, massa fresca e massa seca.

Os tratamentos propiciaram diferenças significativas para o comprimento da maior folha e número de folhas, sendo T4 e T2 que apresentaram os maiores valores, respectivamente.

As análises de macro e micronutrientes na parte aérea da cultura da alface não apresentaram diferenças significativas entre os tratamentos, exceto para o manganês.

Os tratamentos não apresentaram diferenças significativas na extração de macro e micronutrientes pela cultura da alface.

A análise microbiológica demonstrou que, em todos os tratamentos, ocorreu contaminação de coliformes fecais e totais, sendo mais pronunciados em T3 e T4; e nenhuma contaminação de Escherichia coli.

Os Coeficientes de Uniformidade de Christiansen (CUC) encontrados foram acima de 85\% em todos os tratamentos, exceto para o tratamento T3, em que se encontrou $74,05 \%$, indicando que esse tratamento possui maior potencial de entupimento de gotejadores que os demais.

\section{AGRADECIMENTOS}

À Fundação Araucária da Secretaria de Ciência e Tecnologia do Estado do Paraná, pelo apoio financeiro, e ao Curso de Nutrição do Câmpus de Toledo - PR, da UNIPAR, pelo apoio laboratorial nas análises microbiológicas.

\section{REFERÊNCIAS}

ALI, B.I. Irrigation in arid regions. Journal of Irrigation and Drainage Engeneering of ASCE, New York, v.113, n.2, p.173-83, 1987.

ALVES, D.R.B. Efeitos de adubações nitrogenadas via água de irrigação e convencional na produtividade da alface (Lactuca sativa L.). 1996. 76 f. Dissertação (Mestrado em Irrigação e Drenagem) - Universidade Estadual Paulista, Botucatu, 1996. 
ARAUJO, A.L.; KÖNIG, A.; MILANEZ, J.G.; CEBALLOS, B.S.O. Reúso indireto de esgotos na irrigação de colunas experimentais de solo cultivadas com alface (Lactuca sativa L.). In: CONGRESSO BRASILEIRO DE ENGENHARIA SANITÁRIA E AMBIENTAL, 20., 1999, Rio de Janeiro. Anais... Rio de Janeiro: Associação Brasileira de Engenharia Sanitária, 1999. p.111-19.

AYERS, R.S.; WESTCOT, D.W. A qualidade da água na agricultura. Campina Grande: Universidade Federal da Paraíba, 1991. 218 p.

BASTOS, R.K.X.; MARA, D.D. Irrigacion de hortalizas com águas residuales: Aspectos sanitários. In: CONGRESO INTERAMERICANO DE INGENIERIA SANITARIA Y AMBIENTAL, 23., 1992, La Habana. Anais... La Habana: Association Interamericano de Ingenieria Sanitaria y Ambiental, 1992. p.22-8.

BOARETO, A.E.; CHITOLINA, J.C.; RAIJ, B.V.; SILVA, F.C.; TEDESCO, M.J.; CARMO, C.A.F.S. Amostragem, acondicionamento e preparação das amostras de plantas para análise química. In: SILVA, F.C. Manual de análises químicas de solos, plantas e fertilizantes. Brasília: Embrapa Solos, 1999. p.49-73.

BOUWER, H.; IDELOCITCH, E. Quality requirement for irrigation with sewage water. Journal of Irrigation and Drainage Engeneering of ASCE, New York, v.113, n.4, p.219-62, 1987.

CLESCERI, L.S.; GREENBERG, A.E.; EATON, A.D. Standard methods for the examination of water and wastewater. $20^{\text {th }}$ ed. Washington: American Public Health Association, 1998. 989 p.

COSTA-VARGAS, S.M.V.; MARA, D.D.; VARGAS-LOPES, C.E. Residual fecal contamination on effluent irrigated lettuce. Water Science Technology, Londres, v.24, n.9, p.89-94, 1991.

DANTAS, R.T. Parâmetros agrometeorológicos e análise de crescimento da alface (Lactuca sativa L.) em ambiente natural e protegido. 1997. 113 f. Dissertação (Mestrado em Irrigação e Drenagem) - Faculdade de Ciências Agronômicas, Universidade Estadual PaulistaBotucatu, 1997.

DEMATTÊ, J.B.; MORETTI FILHO, J. Influência sobre o desenvolvimento e a produção da cultura da alface (Lactuca sativa L.). Científica, São Paulo, v.9 n.1, p.45-51, 1981.

FERREIRA, M.C. Nutrição e adubação de hortaliças. Piracicaba: Potafós, 1993. 480 p.

FILGUEIRA, F.A.R. Manual de olericultura. 2.ed. São Paulo: Agronômica Ceres, 1982. 687 p.

FONSECA, A.F. Disponibilidade de nitrogênio, alterações nas características químicas do solo e do milho pela aplicação de efluente de esgoto tratado. 2001.95 f. Dissertação (Mestrado em Irrigação e Drenagem) - Escola Superior de Agricultura "Luiz de Queiroz", Universidade de São Paulo, Piracicaba, 2001.

GOMES, T. M. Fertirrigação com diferentes doses de uréia e seu efeito na cultura da alface (Lactuca sativa L.). 1998. 72 f. Dissertação (Mestrado em Irrigação e Drenagem) - Faculdade de Ciências Agronômicas, Universidade Estadual Paulista, Botucatu, 1998.

HAMADA, E. Desenvolvimento e produtividade da alface (Lactuca sativa L.) submetida a diferentes lâminas de água através da irrigação por gotejamento. 1993. 103 f. Dissertação (Mestrado em Água e Solo) - Universidade Estadual de Campinas, Campinas, 1993.

HAMODA, M.F.; AL-AWADI, S.M. Improvement of effluent quality for reuse in a dairy farm. Water Science and Technology, Londres, v.33, n.10-11, p.79-85, 1996.

HUSSAIN, G.; AL-JALOUD, A.A.; KARIMULLA, S. Effect of treated effluent irrigation and nitrogen on yield and nitrogen use efficiency of wheat. Agricutural Water Management, Amsterdam, v.30, n.1, p.175-84, 1996.

JUCHEN, C. R. Reúso de efluentes tratados das agroindústrias de leite e carne sobre a produção da cultura de alface (Lactuca sativa L.) fertirrigada. 2000. 75 f. Dissertação (Mestrado em Engenharia de Sistemas Agroindustriais) - Universidade Estadual do Oeste do Paraná, Cascavel, 2000. 
KALIL, A.J.B. Comparação entre a adubação nitrogenada via fertirrigação por gotejamento e a aplicação convencional na produtividade da alface. 1992. 60 f. Dissertação (Mestrado em Irrigação e Drenagem) - Universidade Federal de Viçosa, Viçosa, 1992.

LIMA, S.M.; HENRIQUE, I.N.; CEBALLOS, B.S.O. de; SOUZA, J.T. de; ARAÚJO, H.W.C de; Qualidade sanitária e produção de alface irrigada com esgoto doméstico tratado. Revista Brasileira de Engenharia Agrícola e Ambiental, Campina Grande, v.9, p.21-5, 2005. Suplemento.

MONTE, H.M.; SOUSA, M.S. Effects on crops of irrigation with facultative pond effluent. Water Science Technology, Londres, v.26, n.7-8, p.1603-13, 1992.

ORON, B.G.; BEM-ASHER, J.; DEMALACH, Y. Effluent in trickle irrigation of cotton in arid zones. Journal of Irrigation and Drainage Engineering, New York, v.108, n.IR2 june, p.115-26, 1982.

ORON, B.G.; DEMALACH, J.; HOFFMAN, Z.; CIBOTARU, R. Subsurface microirrigation with effluent. Journal of Irrigation and Drainage Engineering, New York, v.117, n.1, p.115-26, Jan/Feb., 1991a.

ORON, B.G.; DEMALACH, J.; HOFFMAN, Z.; MANOR, Y. Effluent reuse by trickle irrigation. Water Science Technology, Londres, v.24, n.9, p.103-8, $1991 \mathrm{~b}$.

OSBURN, R.C.; BURKHEAD, C.E. Irrigating vegetables with wastewater. Water Enviroment \& Technology, Alexandria, v.4, n.1, p.38-43, 1992.

PORRÉCA, L.M. ABC do meio ambiente: água. Brasília: IBAMA, 1998. 30 p.

RICCI, M.S.F. Crescimento e teores de nutrientes em cultivares de alface (Lactuca sativa L.) adubados com vermicompostos. 1993. 101 f. Dissertação (Mestrado em Irrigação e Drenagem) Universidade Federal de Viçosa, Viçosa, 1993.

ROWSE, H.R. The effect of irrigation on the length, weight, and diameter of lettuce roots. Plant and Soil, Wellesbourne, v.40, n.2, p.381-91, 1974.

SANDRI, D.; MATSURA, E.E.; TESTEZLAF, R. Teores de nutrientes na alface irrigada com água residuária aplicada por sistemas de irrigação. Engenharia Agrícola, Jaboticabal, v.26, n.1, p.45-57, 2006.

SILVA, F.C. Manual de análises químicas de solos, plantas e fertilizantes. Brasília: Embrapa Solos, 1999. $370 \mathrm{p}$.

SILVA, N; JUNQUEIRA, V.C.A.; SILVEIRA, N.F.A. Manual de métodos de análise microbiológica de alimentos. São Paulo: Varela, 2001. 317 p.

SOUSA, L.M.A. Manejo da fertirrigação potássica na cultura da alface (Lactuca sativa L.) americana. 2000. 63 f. Dissertação (Mestrado em Irrigação e Drenagem) - Faculdade de Ciências Agronômicas, Universidade Estadual Paulista, Botucatu, 2000.

SPERLING, M.V. Introdução à qualidade das águas e tratamento de esgotos: princípio do tratamento biológico das águas residuárias. 2.ed. Belo Horizonte: Universidade Federal de Minas Gerais, 1996. v.1, 125 p.

TAVARES, T. de L.; KÖNIG, A.; CEBALLOS, B.S.O. de; AZEVEDO, M.R. de Q.A. Efeitos da adubação do solo e da irrigação sobre os componentes de produção da alface. Revista Brasileira de Engenharia Agrícola e Ambiental, Campina Grande, v.9, p.231-5, 2005. Suplemento.

VAZQUEZ-MONTIEL, O.; HORAN, N. J.; MARA, D. D. Management of domestic wastewater for reuse in irrigation. Water Science Technology, Londres, v.33, n.10-11, p.355-62, 1996. 